\title{
URBAN PLANNING AND ECONOMIC DEVELOPMENT OF NEPAL
}

\author{
Krishna Raj Acharya*
}

\begin{abstract}
Urban planning is an integral part of economic planning. The concept of planning has became more popular because of answering the questions; what to produce, how to produce and to whom should be produced. If there is a proper planning in urban areas of any country, then economic development is possible in those nations. In this paper, attempts were directed to explore the relationship between dependent and affecting variables (independent variables) in the time of study of urban planning. It concluded that there is no association among urban growth and urban population, number of urban areas as well as urban population percent. The identified urban indicators are regressed with urban growth which reveals that the variables are not best fitted so that the development of our nation is still in the verge of obstacle. $P$ value of all these independent variables are insignificant $(P>0.05,0.87$ coefficients of urban population percent, 0.72 coefficient of number of urban areas and 0.09 coefficient of national population growth $>0.05$ ).
\end{abstract}

Keywords: Urban planning, economic development, variables, resources, population

\section{INTRODUCTION AND OBJECTIVE}

Planning is the systematic way of doing certain work. Basically in economic planning three components are included into analysis. They areobjectives, resources for the fulfillment of that objective and certain time period. The concept of planning was first of all propounded and implemented from the side of former USSR in 1928 AD. Due to their economic plan of that time, their economy was not affected from the great depression of 1930s decade. Thereafter, the concept of plan became worldwide. Planning is useful to mobilize the available resources according to the intensity of wants so that there is a greater chance of being rapid economic development in the country. Similarly, economic development is a process whereby real per capita income of the people increase over the long time period. It is

* Dr. Acharya is an Associate Professor of Economics, Ratna Rajyalaxmi Campus, Bhrikuti Mandap, TU. 
only possible when we have a good planning. Economic planning in each country is to accelerate the pace of economic development. If planning is formulated and implemented properly and effectively then it will be a key role for the utilization of available resources.

The geographical location of Nepal is panoramic in the sense that it has lot of beautiful places. The Himalaya, mountains and the Terai constitute Nepal. The highest peak of Mt. Everest with several peaks of the Himalayas is the center of attraction for courageous tourists. Nepal is the one of the best countries in the world with specialties of the large mountain areas, the beautiful structure of those mountains, multi religious, multi lingual, multi ethnic and multi culture (Parajali, 2008). As of other nations, Nepal has rural as well as urban areas. Development of the nation is relying on the planning and management of these areas.

In every country, there are two sectors. They are rural sector and urban sector. Economic planning incorporates both rural and urban planning. In the absence of rural planning, the dream of urban planning cannot be materialized. For example, we have a plan of establish the industries in the urban areas of Nepal but there is lack of rural plan to produce raw materials then it cannot convert into reality. So that rural and urban planning and development are complementary rather than substitute. In the absence of one, the value of next will be nil.

Earlier, Nepal had 217 cities and 3157 famous villages with fame and specialties because they all have different culture, natural resources and other special identities. Later on, the data was changed as the commission of Restructuring in Federalism has decided 774 local bodies in Falgun of 2073 which constitute 7 provinces, 77 districts, 6 metropolises, 11 sub metropolis, 276 municipalities and 481 rural municipalities. The recommended local bodies are listed in the red book of the government and it is implemented practically. The concept of one metropolis in one state according to government policy has been neglected. For example there are three metropolises in a province three of Nepal and other provinces have no metropolis in Nepal. The government's such irrational activity has been heavily criticized by the people. Nepal is a country of villages in the sense that even it is declared as urban, they are like of rural and backward. So, there is no way to develop our nation until and unless village is not in the mainstream of development. It is quite essential to increase the rural 
agrarian production, productivity and skill to ensure peace, progress and prosperity in the faces of rural dwellers.

\section{Conceptualizing Urban Planning}

Urban planning is the systematic efforts to develop the area where development strategies are carried out with certain objectives and defined resources. The concept of planning became more popular due to the limited resources. Limited resources should be used where it is more productive. It is basically decided on the basis of various criteria. Cost benefit ratio, net present value and internal rate of return are basic instruments that used before investing in capital assets. In Nepal, the concept of planning was systematically forwarded in 2013 BS even it was informally implemented in Rana regime. We completed more than a half century of our systematic manner of work. But in real sense, we are not getting as we expected from our plans due to various imperfections in the market and acute shortage of resources. So that urban planning implies the systematic and planned work of the urban areas. For example, wide and clean road, employment opportunities, proper sanitation and health facilities, pure drinking water, development of secondary sectors, solid waste management, and appropriate space that required in the time of evacuation when natural calamities are the components of urban planning.

A city is not only collection of buildings, and it is more than a collection of human beings. It must have at least some minimum of structure, with identifiable roles and status positions. It is more amorphous than a corporation, more structured than a crowd. Although it has a political definition, the operational city frequently does not coincide with the political boundaries, and the economic structure likewise fails to conform to the political unit. Despite these difficulties, all of us seem to agree that there is an identifiable phenomenon called a city; that there is, indeed, a class of such phenomena; and that these cities have certain properties which can be studied by scientific methods. It is possible to represent the city as a system characterized by a feedback loop involving human efforts, capital equipment, and goods and services. (There are numerous other feedback loops within this one, for ex- ample, the population-garbage-disease cycle, which will be ignored in this paper.) A psychological approach to this urban system proposes that we focus on the human beings who are the atoms, the irreducible units of the system. Inputs into the urban process include human talents, skills, and energies; human outputs include consumable goods and 
income, services, suffering, goal- achievements, and satisfactions. By this definition, criminal behavior may be an output, as well as the pain of the victim; the production of music by a symphony orchestra is another service output, and the enjoyment of the listener is an out- put of a different kind, but, nevertheless, not one to be ignored. For convenience, the traditional out- puts (commodities, street-maintenance, school-operation, and the like) are separated from the psychological outputs (anxieties, hostilities, frustrations, and satisfactions). In any real observation of the city, of course, there is a close linkage of the two categories (Stagner, 1970).

\section{Current Urban Condition of Nepal}

Urban database system on land and infrastructure related variables is poor and far from comprehensive and reality. Land fragmentation, unregulated and informal urban land market, cumbersome land acquisition and compensation mechanism and lack of comprehensive zoning regulations and land use controls characterize the prevailing conditions of urban land. The supply of serviced land is limited and urban sprawl is at the expense of productive agricultural land. The evolving urban form is becoming increasingly disorganized with incompatible land uses pattern and declining level of amenities and neighborhood environment in Nepal (MoUD, 2017).

Lack of urban infrastructures is highlighted by the condition of water supply, sanitation, solid waste management, housing pattern, transport and energy. There is considerable disparity among ecological regions. Only 32.9 percent of households have access to piped water supply in urban Tarai as compared to 81.2 percent of households in urban hill. The quality and quantity of drinking water is insufficient and untimely in all urban regions. To meet the MDG target of water for all by 2017, substantial investment to the tune of Rs. 7.5 billion per annum is required to be spent. Conditions of sanitation system and solid waste management are also critical. Only 56.1 percent of urban households have access to sanitation system with 88.2 percent households having access to toilets. Likewise, out of 58 municipalities, only 6 have sanitary landfill sites and only 5 practices controlled waste dumping reflect worse situation (MoUD, 2017)

Lack of affordable housing and increasing squatter settlements are major problems in the urban housing sector, which is evident in the growing housing deficit and increasing percentage of squatter settlements in urban areas. Squatters settlement comprise an approximately 10 percent 
of the urban population, but some urban areas have three times of such problem like Dharan. Inadequate, unproductive and inefficient transport infrastructure is a critical concern in urban transportation sector. The average road density of urban areas is $3.26 \mathrm{~km} / \mathrm{sq} . \mathrm{km}$, which is inadequate for the efficient urban mobility as well as to promote urban rural linkages. The national energy crisis is apparent and exaggerated in the urban area. The demand of electricity is the highest in urban and industrial corridors with an annual rate of increment of 9 percent but it is not available in reasonable rate. Demand for electricity is high when it compared the supply in urban areas.

To assess the infrastructural status of various municipalities, an Urban Infrastructure Condition Index (UICI) was computed for 58 municipalities. UICI provides a tool for comparison of infrastructural condition of municipalities. Kathmandu Metropolitan City has the highest value of UICI whereas Gulariya remains at the bottom of the index list. Urban areas are regarded as the engines of economic growth. The recent GDP data by CBS shows that urban areas directly contributed 33.1 percent to the national GDP (NPC/ UNDP 2014) and another 30 percent comes from the VDCs at proximity to or served by the urban centers. The contribution of urban areas to the GDP provides stronger justification for investing in urban infrastructure because it facilitates in the generation of wealth and employment opportunities and boosts the rate of economic growth (MoUD, 2017).

Agriculture and its related activities account for one-third of the total employment in the urban sector. Wholesale and retail trade and manufacturing contribute 17 percent and 14 percent of urban employment respectively. Poverty in urban areas is rising. In 2003/04 about 10 percent of urban population was lying below the poverty line. The 2010/11 NLSS shows that population below poverty line comprises 15 percent of the total urban population. There are significant differences between urban areas Pokhara has only 1.3 percent below poverty line while in Gulariya, it is 50 percent which is quite high than that of Pokhara (MoUD, 2017).

\section{Planning and Development in Nepal}

In normal sense, economic planning and development have positive relationship. It was realized in the tome of great depression of the world by former USSR. Their economy was safe from the big blow of depression in that time. Without proper plan, there is a chance of misuse of scarce 
resources. Urban and rural planning can be summarized in a plan of a nation because country is a summation of rural and urban areas.

Over the years, the economic growth rate has lingered between three and four per cent. Nepal needs to ensure stable economic growth to meet the target of 5.5 per cent growth by 2015. Agriculture still employs the majority of the workforce in the country, and thus immediate steps need to be taken to enhance production capacity through innovative means and new technology. The immediate challenge is to deal with the energy crisis as the country faces 56 hours of load-shedding per week. It also has to ensure good governance, inclusive development and sustainable growth in the near future. It is also necessary to undertake strategies to invest in some large infrastructures such as mid-hill highways, Kathmandu-Tarai Fast Track, mega power plants etc (ORF, 2015)

However, the most immediate challenge is of political stability as without this no economic programme or policy can be prepared or implemented. The political instability and the inability of the political parties to conclude the peace process and Constitution-writing have severely hampered Nepal's development prospects. Foreign investment is lacking in major sectors like infrastructure and hydro-power development. Industry is suffering and donor-funded projects remain incomplete. The transition to an equitable and inclusive development requires political stability, which has been illusive in Nepal since 1990's. There are opportunities for Nepal's growth mainly through development of hydro sector and expansion of market as a "bridge" between two giant economies of the world - India and China. The political class should realize this immense opportunity knocking Nepal and resolve the political tensions at the earliest for the sake of peace, development and well-being of all Nepalese people (ORF, 2015).

In summary, there is a positive relationship between economic planning and development in the sense that it allocate and use of human and natural resources in most productive sectors. If there is a planning of urban area then the resources available in that area utilized properly, efficiently and effectively. Natural resources should be balanced with the size of population of that area. If there is no association between these two variables, then there is a problem of over utilization and underutilization quantitative as well as qualitative aspects of both (rural and urban) areas should take as a part of analysis. . 


\section{METHODOLOGY}

This paper was prepared on the basis of existing stock of knowledge of the presenter and different data and literature available in the time of study. Previous development plans of Nepal with expected growth and actual growth were taken as a instrument of analysis. In Nepalese context, plans, resources allocation and actual returns were analyzed with the help of available literature in this paper. To explore the relationship between economic plans and development was the main objective of this paper and existing stock of knowledge were used to reach in the conclusion in this assigned task. Secondary data were used to explain about various micro and macro variables. To some extent, questions were asked to the dwellers of urban area and write the conclusion on the basis of their answers. Some of the writing is based on the observation from the side of presenter. Some data were taken from economic surveys, budget speech and various five and three years interim plans of Nepal.

Model was developed to explore the relationship between dependent and independent variables.Urban population percent, number of urban areas and national population growth were taken as independent variables while urban growth was dependent variable. Model was specified as;

$Y=\beta_{0}+\beta_{1} X_{1}+\beta_{2} X_{2}+\beta_{3} X_{3}$

$\mathrm{Y}=$ Urban Growth, $\mathrm{X} 1_{=}$Urban Population (in percent), $\mathrm{X}_{2=}$ Number of Urban Areas and

$\mathrm{X}_{3=}$ Urban Population Growth

\section{ANALYSIS}

This section incorporates process of urban planning and current practices of Nepal.

\section{Process of Urban Planning and Economic Development}

Urban planning was started in Nepal before implementation of five year economic plan in 1956. Before that time period, people are centered in the areas where there are fertile land, employment opportunities and others facilities. Slowly, people started to shift from hills and Himalayan regions to Terai areas, ultimately large number of population leads toward urban centers. Now, those centers have lot of problem due to influx of population and heavy encroachment on natural resources. Growth of population and their management were two basic components for the rise of urban sector in 


\section{URBAN PLANNING AND ECONOMIC DEVELOPMENT IN NEPAL}

Nepal. The rise of urban sector is rapid after the declaration of new federal structure of Nepal.

Table1: Urban growth patterns in Nepal

\begin{tabular}{|c|c|c|c|c|c|}
\hline $\begin{array}{c}\text { Year/ } \\
\text { Variables }\end{array}$ & $\begin{array}{c}\text { Urban } \\
\text { Population } \\
(000)\end{array}$ & $\begin{array}{c}\text { No. of } \\
\text { Urban } \\
\text { areas }\end{array}$ & $\begin{array}{c}\text { Urban } \\
\text { Population } \\
(\%)\end{array}$ & $\begin{array}{c}\text { Urban } \\
\text { Growth }\end{array}$ & $\begin{array}{c}\text { National } \\
\text { Population } \\
\text { Growth }\end{array}$ \\
\hline 1961 & 336 & 16 & 3.6 & 4.4 & 1.65 \\
\hline 1971 & 462 & 16 & 4 & 3.2 & 2.07 \\
\hline 1981 & 957 & 23 & 6.4 & 7.5 & 2.66 \\
\hline 1991 & 1696 & 33 & 9.2 & 5.8 & 2.1 \\
\hline 2001 & 3228 & 58 & 13.9 & 6.6 & 2.27 \\
\hline 2011 & $4523^{*}$ & $58^{*}$ & $17^{*}$ & $3.4^{* * *}$ & $1.35^{*}$ \\
\hline 2014 & 5130 & 191 & 18.2 & 4.1 & 1.35 \\
\hline
\end{tabular}

Source: Adapted from Choe and Pradhan(2010: p.7)

* CBS (2012), ** UN DESA(2014), *** MoUD(2015)

The number of population in the urban areas is increasing year after year. But the facilities of the urban areas remain unchanged. The number of urban center is also increasing due to the internal migration of people from hill to Terai and district headquarters of Nepal.The economic activities of this region cannot increase as it is expected from the side of policy makers. So that the rate of economic development is slow in Nepal.

Urbanization is an index of transformation from rural economy to modern industrial one. It is consider as an integral part of the process of human civilization, economic transformation and development. Urbanization has positive change than negative change on social change. Number of urban places increased from 10 in 1952/53 to 191 in 2014. Urbanization in Nepal has spatial characteristics. There is a regional variation in level of urbanization. It range from 14.3 percent to 40.3 percent in ecological zones, 25.9 percent to 47.3 percent in development regions and 4.9 percent to 64.3 percent in ecological regions. The level of urbanization ranging from a low of 6 percent for Rolpa district to a high of 100 percent for Kathmandu and Bhaktpur districts (Thapa, 2074). 
Table 2: Log Values of Urban Population, Number of Urban Areas, National Population Growth \&Urban Growth.

\begin{tabular}{|c|c|c|c|c|}
\hline Years & $\begin{array}{c}\text { LNURBAN_ } \\
\text { GROWTH }\end{array}$ & LNUPOPC & LNUAREA & LNNPG \\
\hline 1961 & 1.481605 & 1.280934 & 2.772589 & 0.500775 \\
\hline 1971 & 1.163151 & 1.386294 & 2.772589 & 0.727549 \\
\hline 1981 & 2.014903 & 1.856298 & 3.135494 & 0.978326 \\
\hline 1991 & 1.757858 & 2.219203 & 3.496508 & 0.741937 \\
\hline 2001 & 1.88707 & 2.631889 & 4.060443 & 0.81978 \\
\hline 2011 & 1.223775 & 2.833213 & 4.060443 & 0.300105 \\
\hline 2014 & 1.410987 & 2.901422 & 5.252273 & 0.300105 \\
\hline
\end{tabular}

Source: Based on Table 1 \& Processed by Applying Eview 9 software

Our given data were converted as log value(first order differentiation) tp make the value more symmetrical and bell shaped. It is still taken as a important step in the process of model building in the context of statistical analysis. Now descriptive statistics of the table 2 can be estimated as;

Table 3: Descriptive Statistics of above listed Variables

\begin{tabular}{|c|c|c|c|c|}
\hline & $\begin{array}{c}\text { LNURBAN_ } \\
\text { GROWTH }\end{array}$ & LNUPOPC & LNUAREA & LNNPG \\
\hline Mean & 1.562764 & 2.158465 & 3.650048 & 0.624082 \\
\hline Median & 1.481605 & 2.219203 & 3.496508 & 0.727549 \\
\hline Maximum & 2.014903 & 2.901422 & 5.252273 & 0.978326 \\
\hline Minimum & 1.163151 & 1.280934 & 2.772589 & 0.300105 \\
\hline Std. Dev. & 0.329619 & 0.669913 & 0.888086 & 0.262523 \\
\hline Skewness & 0.136551 & -0.20365 & 0.709441 & -0.15116 \\
\hline Kurtosis & 1.541482 & 1.466549 & 2.470435 & 1.628792 \\
\hline Jarque-Bera & 0.642209 & 0.734232 & 0.668986 & 0.575053 \\
\hline Probability & 0.725347 & 0.692729 & 0.715701 & 0.750117 \\
\hline Sum & 10.93935 & 15.10925 & 25.55034 & 4.368576 \\
\hline Sum Sq. Dev. & 0.651893 & 2.692702 & 4.732184 & 0.413509 \\
\hline Observations & 7 & 7 & 7 & 7 \\
\hline
\end{tabular}

Source: Based on Table 2 and Analyzed by Using Eview 9 Software.

Nepal is one of the ten least urbanized countries in the world. However, it is also one of the top ten fastest urbanizing countries. In 2014, 


\section{URBAN PLANNING AND ECONOMIC DEVELOPMENT IN NEPAL}

the level of urbanization was 18.2 per cent, with an urban population of $5,130,000$, and a rate of urbanization of 3 percent. For the period 2014-2050, Nepal will remain amongst the top ten fastest urbanizing countries in the world with a projected annual urbanization rate of 1.9 per cent (UNDESA, 2014). Urbanization in Nepal is dominated by a few large and medium cities with an excessive population concentration in the Kathmandu Valley. High urban growth is occurring in the Kathmandu Valley, the Pokhara Valley, the Inner Tarai valleys, and in market and border towns located on highway junctures between the east-west highway and the five main northsouth corridors. Urban growth centers are also emerging close to the border with India (Muzzini\&Apericio, 2013). On the basis of table 2, we have a regression analysis on the basis of Eview 9.

Table 4: Results of Regression Analysis

\begin{tabular}{|c|r|r|r|r|}
\hline Variable & Coefficient & Std. Error & t-Statistic & Prob. \\
\hline LNUPOPC & 0.068594 & 0.399337 & 0.171770 & 0.8746 \\
\hline LNUAREA & 0.126601 & 0.325456 & 0.388996 & 0.7232 \\
\hline LNNPG & 1.208896 & 0.496620 & 2.434247 & 0.0930 \\
\hline C & 0.198155 & 0.787020 & 0.251779 & 0.8175 \\
\hline R-squared & 0.683674 & Mean dependent var & 1.562764 \\
\hline Adjusted R-squared & 0.367348 & S.D. dependent var & 0.329619 \\
\hline S.E. of regression & 0.262177 & Akaike info criterion & 0.455966 \\
\hline Sum squared resid & 0.206211 & Schwarz criterion & 0.425058 \\
\hline Log likelihood & 2.404117 & \multicolumn{2}{|c|}{ Hannan-Quinn criter. } & 0.073943 \\
\hline F-statistic & 2.161296 & Durbin-Watson stat & 2.863033 \\
\hline Prob(F-statistic) & 0.271511 & \multicolumn{3}{|l}{} \\
\hline
\end{tabular}

Source: Based on Table 2 and Processed through Eview 9 Software.

On the basis of given information, we can conclude that there is no association among urban growth and urban population, number of urban areas as well as urban population percent. In other words, they are statistically insignificant. No relationship among variables of urban indicators reveals that variables are not best fitted so that the development of our nation is still in the verge of obstacle. It can mathematically express as;

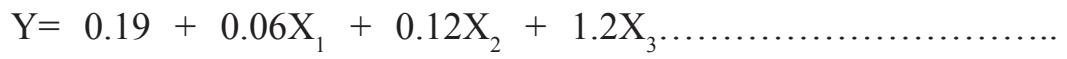

Where,

$Y=$ Urban Growth, $X_{1=}$ Urban Population (in percent), $X_{2=}$ Number of Urban Areas

$\mathrm{X}_{3=}$ Urban Population Growth 
Urban planning in Nepal is not satisfactory because there is no close relationship among the desired variables. No urban planning, the rate of development is certainly slow which is true in Nepalese context.

\section{Current Practices of Urban Planning in Nepal}

Urban planning is the systematic function of the urban area but the role of rural should not be overlooked. In these days, population criteria if fulfilled then it declared as an urban area in Nepal. In Nepal, population size is taken as a indicator of urban area. In urban areas of Nepal, manpower planning is hazardous so that production is less. Water supply in most of the cities of Nepal is inadequate and of low quality. Appropriate type of education and health services are rare in Nepalese urban area which is the basic service of such areas. Pollution level of Nepalese cities is very high which easily can be realized with simple observation. Waste management is a basic problem of Nepalese cities so that the dwellers of urban areas are facing the problem from such type of waste. All the variables of urban area are not actually met from our side so that there is low rate of economic growth. It is due to lack of urban planning in Nepal. In the time of developing cities in Nepal, environmental aspect still is not taken into analysis. So that, the rate poor is more rapid due to cities of Nepal.

The urban population living below poverty lone was 10 percent in fiscal year 2003/04. While, it was went up to 15 percent in fiscal year 2010/11. Urban poverty gap varies substantially across Nepal. Population living below poverty line is 1.3 percent in Pokhara while that of Guleria is 50 percent (Economic Survey, 2017). Contribution of urban sector to gross domestic product (GDP) is 33.1 percent. Contribution of village development committee in proximately to urban areas enjoying urban facilities accounts for 30 percent (UNDP, 2014).

\section{CONCLUSIONS}

After the study in this presented paper, we know that planning and growth of a nation are two inseparable parts as two sides of same coin. It was empirically verified in the time of economic depression of 1930s. Health, education, employment, space management, waste management, pure drinking water, less dust and smoke, people with awareness, dominant of secondary sector are the basic prerequisite for the urban (cities) areas. We can easily claim the poor real situation with the help of observation. In our data there is no strong statistical association between dependent (urban growth) and independent variables (number of cities, urban population size 
and urban population percent). The probability value of all these independent variables is higher than 0.05 ( 0.87 coefficient of urban population percent, 0.72 coefficient of number of urban areas and 0.09 coefficient of national population growth $>0.05$ ) so that there is no association among them.

\section{ACKNOWLEDGEMENTS}

The author deserve thanks to the Institute of Social Development and Research, Ranchi for providing an opportunity to present a paper entitled "Urban Development" which was held on 10-12 March, 2018.

\section{REFERENCES}

CBS.(2014). National population and housing census 2011: Urban tables. Kathmandu: Author.

MoF (2017).Economic survey. Kathmandu: Ministry of Finance.

MoUD(2015). National urban development strategy. Kathmandu:Author.

- - - (2017). National urban development strategy. Kathmandu: Author.

Muzzini, E. \&Aparicio, G. (2013).Urban growth and social transition in Nepal. Washington D.C: World Bank.

ORF (2015).Annual report 2015. Delhi India: Author.

Parajuli (2008).Citizen Perception about Green Space Park in Pokhara. Himalayan Journal of Sociology and Anthropology, Vol (3), pp. 3445

Stagner, R. (1970). Perceptions, Aspirations, Frustrations, and Satisfactions: An Approach to Urban Indicators. The Annals of the American Academy of Political and Social Science, (388), 59-68. Retrieved from http://www.jstor.org/stable/1038316

Thapa, N.R (2074). Urban demography in Nepal. RR Interdisciplinary Journal.Vol.( 1), pp. 142-150

UNDESA (2014). World urbanization prospects: 2014 revision. New York: Author.

UNDP (2014). Nepal annual report. Washington D.C. United Nation Development Program. 